\title{
$\mathrm{PH} 101_{\text {cosate }}$
}

a debate Hacia una nueva institucionalidad cultural. Modelos emergentes de gestión...

| coordina Jesús Carrillo Castillo

\section{Archivos: instituciones culturales para la ciudadanía}

\author{
Mateo A. Páez García | Archivo General de Andalucía \\ URL de la contribución <www.iaph.es/revistaph/index.php/revistaph/article/view/4732>
}

Hay una institución cultural que no puede ser ajena a este debate que se plantea: los archivos. En estos centros pugna su doble naturaleza administrativa y cultural ya que, por un lado, son unidades fundamentales en el engranaje administrativo, encargadas de formular y aplicar una adecuada gestión documental en las entidades y organizaciones. En este sentido, los documentos que estas generan en el ejercicio de sus funciones constituyen evidencias, con valor legal, de derechos y deberes de la Administración y de la ciudadanía, que deben ser debidamente conservados para seguridad jurídica de ambas. Por otro lado, los archivos son centros de cultura que custodian y difunden la memoria de una sociedad en forma de documentos.

En ambas perspectivas, la relación de estas instituciones con la ciudadanía ha experimentado fuertes cambios desde el último cuarto del siglo XX. Posiblemente el más intenso se ha dado en los archivos como instituciones administrativas, centrado en el derecho de acceso a los archivos y a los documentos como un instrumento esencial de la transparencia en la actuación pública: sin acceso a los testimonios documentales, que contienen de manera íntegra, auténtica y fiable la información pública, es imposible auditar la actuación de los poderes públicos y la exigencia de rendición de cuentas; los derechos ciudadanos se ven amenazados; y la calidad democrática de una sociedad se resiente.

Pero, ¿qué sucede con los archivos como instituciones culturales? Aquí los cambios son también profundos, pero aún estamos inmersos en ellos. Podemos sintetizarlos en la demanda ciudadana activa de los servicios de archivo (IACOVINO, 2013), que consisten básicamente en conservar y tener disponible la memoria en forma de documentos. Esto que se enuncia tan fácilmente requiere una serie de tareas técnicas sobre los documentos (organización, descripción, clasificación) y unas infraestructuras (depósitos, estanterías, contenedores especiales) que garanticen debidamente la conservación a perpetuidad de documentos en los más variados soportes: papel, pergamino, celuloide, cintas magnéticas, documentos electrónicos, etc., lo que conlleva elevados costes.

Los archivos públicos tienen un compromiso con la sociedad que los mantiene y, por lo tanto, no solo pueden ser memoria de las Administraciones que los crean. Esta misión no es nueva; ha sido cumplida desde siempre por los archivos, abiertos a albergar fondos privados del más diverso origen (familiares, empresariales, de entidades y asociaciones, colecciones temáticas, fotográficos, etc.). Pero ello se hacía valorando la singularidad y relevancia de la persona o institución que creaba el fondo o formaba la colección.

En los inicios del siglo XXI se da un cambio trascendental. Por buscar el simbolismo de una fecha en nuestro país, esta puede ser la del 15 de marzo de 2011. Independientemente de cualquier consideración política al respecto, el movimiento del 15M lanzaba la idea radical, de que "cualquier material es susceptible de perdurar en el tiempo, tanto como objeto histórico como manifestación política de la voluntad popular" (ARCHIVO 15M, 2015). Solo días después del comienzo de las acampadas comenzaron a conformar un archivo con pancartas, carteles, testimonios fotográficos y videográficos, instalaciones efímeras y materiales muy diversos, considerados como objetos del discurso ciudadano que habían de conformar el archivo. Lo hemos vuelto a vivir con ocasión de la pandemia causada por la Covid-19 y la exigencia ciudadana de documentar todo este proceso y de que todo ello quede custodiado en las instituciones adecuadas.

Estas nuevas exigencias en torno a lo que se ha dado en llamar "archivos ciudadanos" (que ya genera una amplia 
_a debate Hacia una nueva institucionalidad cultural. Modelos emergentes de gestión...

| coordina Jesús Carrillo Castillo

literatura) plantean desafíos profundos al concepto tradicional de archivo. Sin ánimo de exhaustividad, enumeramos algunos:

$>$ Concepto diluido de documento: frente al concepto tradicional, con unas características diplomáticas bien definidas para asegurar su autenticidad, integridad y fiabilidad, el concepto se amplia hasta casi diluirse: redes sociales, blogs, archivos gráficos particulares y, en definitiva, "cualquier material".

$>$ Esto plantea problemas no solo de conservación, sino acerca de la idoneidad de los archivos públicos para conservar estos materiales. Muchas iniciativas ciudadanas han recurrido bien a espacios webs que requieren un mantenimiento constante que no han podido garantizar, bien al uso de la nube, que plantea problemas en torno al control de los materiales dispuestos en ella.

> Cocreación: derecho de los protagonistas no ya solo a aportar sus propios documentos a las instituciones archivísticas, sino a aportar sus propias narraciones a los documentos ya obrantes en ellas, que incluye el derecho al olvido y la eliminación de testimonios, en oposición frontal con la noción de integridad de los documentos y los fondos.

> Cogestión: participación colectiva en la elaboración de instrumentos de descripción archivística (como las sesiones públicas de etiquetado de documentos gráficos) y,

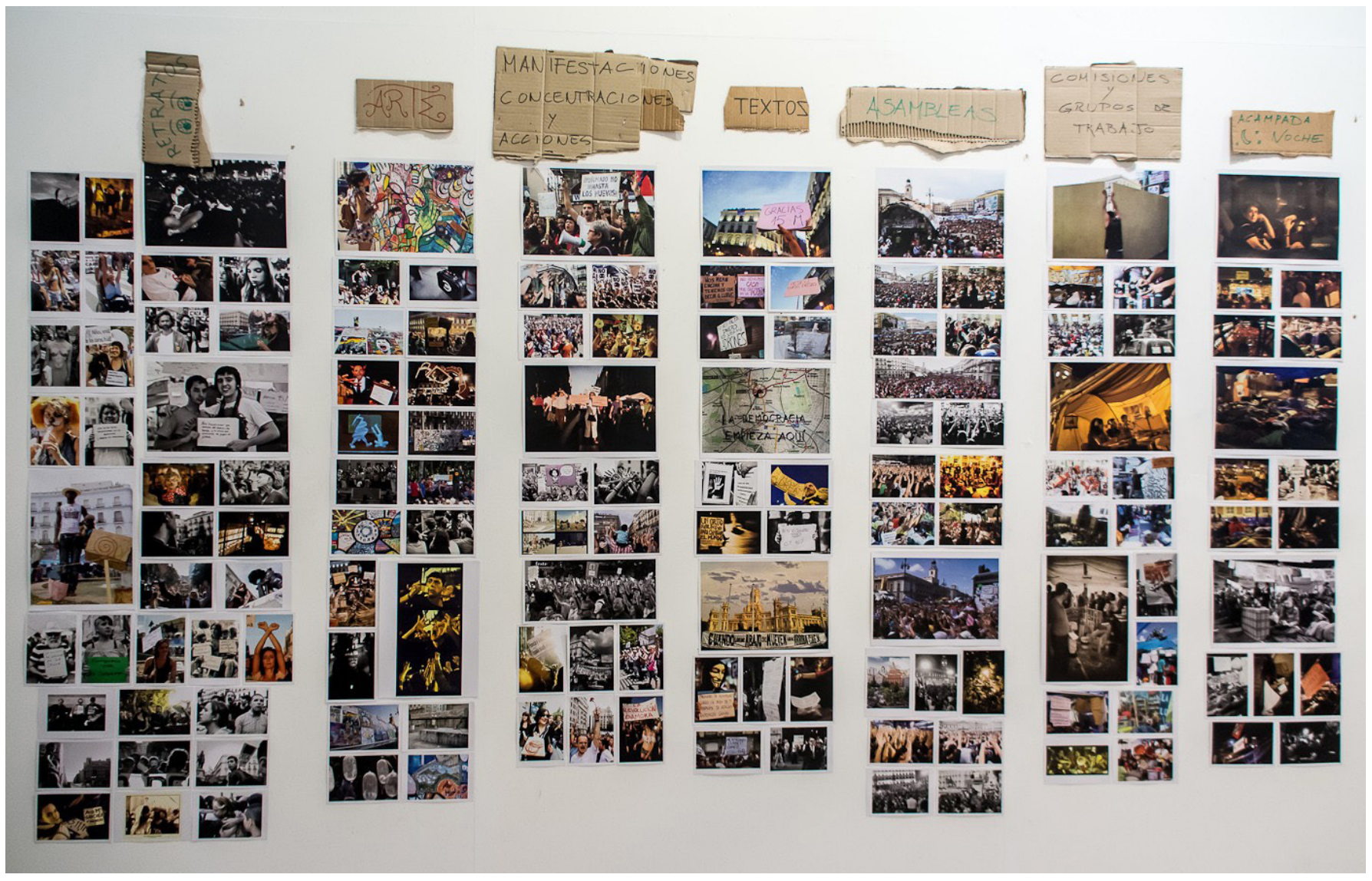

15M 1er Año-II | foto @ondasderuido 
a debate Hacia una nueva institucionalidad cultural. Modelos emergentes de gestión...

| coordina Jesús Carrillo Castillo

por supuesto, participación en la toma de decisiones sobre valoración, acceso y control de los documentos.

> La cuestión del acceso dista de estar cerrada: por un lado, está la necesidad de acceder a documentos del pasado inmediato para asuntos de defensa de derechos humanos (abusos sexuales, robo de niños, justicia transicional, etc.); pero, por otro, no basta el acceso libre a todas las personas, pues siempre habrá colectivos no preparados o con serias limitaciones para ello, por lo que es necesario un acceso especial.

> Intervención activa de los archivos como centros de participación y de conformación de identidad comunitaria.

> El papel del archivero: ¿quién decide sobre qué documentar? ¿hay que atender todas las demandas o establecer también una valoración de las mismas? ¿cómo mantener una postura ética de los archiveros de instituciones gubernamentales cuando deciden conservar o liberar documentos de interés público contra sus propios gobiernos?

\section{NOTAS}

1. Deborah Jenkins ha trazado el camino que va desde el archivero como proveedor imparcial de información a investigadores acreditados de mediados del siglo XX (recordemos que en nuestro país, hasta su supresión por el Real Decreto 1266/2006, de 8 de noviembre, se exigía para acceder a los archivos estatales la Tarjeta Nacional de Investigador, para cuya expedición se necesitaba el aval de un profesor universitario y la acreditación de una investigación histórica en curso), hasta el archivero/a activista del siglo XXI (JENKINS, 2018).

\section{BIBLIOGRAFÍA}

- ARCHIVO 15M (2015) ¡Importante! No basura. Carteles, pancartas. ¡Archivo! Tábula [en línea], n. ${ }^{\circ}$ 18, 2015, pp. 137$147<$ <ttps://publicaciones.acal.es/tabula/article/view/611> [Consulta: 24/07/2020]

- IACOVINO, L. (2013) La participación de los usuarios y el activismo archivístico: pilares de la responsabilización, identidad y justicia reparadora en la propia autenticación del archivo digital. Tábula [en línea], n. ${ }^{\circ}$ 16, 2013, pp. 103$121<$ <ttps://publicaciones.acal.es/tabula/article/view/122> [Consulta: 24/07/2020]

- JENKINS, D. (2018) Archives Services in the Twenty First Century. TRIA [en línea], n. ${ }^{\circ} 22,2018$, pp. 19-29 <https://www. archiverosdeandalucia.org/wp-content/uploads/2019/10/TRIAn\%C2\%BA-22-Deborah-Jenkins.pdf> [Consulta: 24/07/2020] 